\title{
Diagnóstico: antes, durante e depois
}

Diagnostic: before, during and after

Ricardo Peres do Souto

\begin{abstract}
$\mathrm{D}$ iagnóstico, em ciências da saúde, é a conclusão de um processo investigativo acerca de uma situação, usualmente um quadro clínico, sendo fundamental para a tomada de decisão sobre a continuidade do procedimento. Os artigos deste fascículo dos Arquivos Brasileiros de Ciências da Saúde discutem diferentes questões relacionadas ao diagnóstico:
\end{abstract}

Christofolini et al. (pág. 22) desenvolvem e discutem alternativas metodológicas para ampliar o arsenal diagnóstico para uma condição rara e grave, a Síndrome do Termor/Ataxia, manifestada após 50 anos em homens, e descrevem os esforços para a validação de sua aplicação prática;

Forsait et al. (pág. 6) avaliam o impacto do conhecimento da conclusão diagnóstica pelo paciente e seus familiares, particularmente no caso da avaliação de condições que podem estar associadas a estigmas;

Silva et al. (pág. 15) coletam informações sobre o serviço de informação e atualização de profissionais em um hospital público para realizarem um diagnóstico sobre o funcionamento desse setor de apoio, de forma que se permita o planejamento de ações futuras que reafirmem as qualidades do serviço e corrijam eventuais inadequações.

Laczynski et al. (pág. 27) relatam um caso clínico de manifestação incomum (líquen plano em crianças), implicando na ocorrência de tratamentos ineficazes até que seja realizado o diagnóstico correto e a resolução do problema torna-se possível.

Finalmente, celebrando os dez anos do início das atividades do Curso de Enfermagem da Faculdade de Medicina do ABC, a revista traz os resumos dos trabalhos de conclusão dos enfermeiros formados nesse período. Esse rico material traz importantes informações sobre a realidade do curso e para a discussão de seu futuro. 